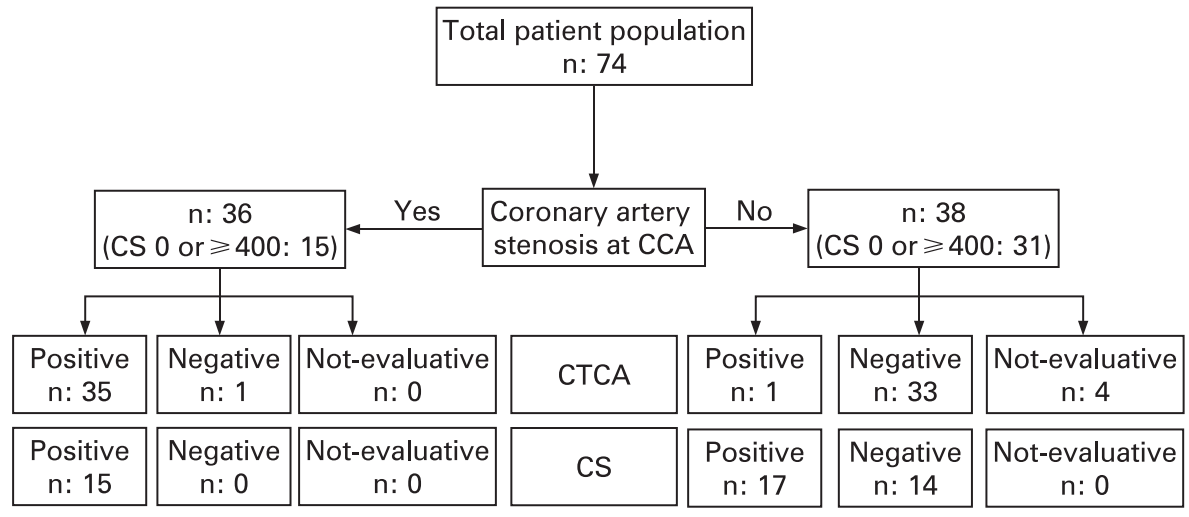

Figure 2 Flow-diagram showing classification of coronary artery stenosis based on calcium scoring (CS; thresholds of 0 and $\geqslant 400$, respectively) and computed tomography coronary angiography (CTCA) in comparison with conventional coronary angiography (CCA).

$100 \%$ each, when applying Agatston score thresholds of 0 and $\geqslant 400$.

We thank Drs Vliegenthart Proença and Oudkerk for their considerations of the role of coronary calcium scoring in the management of patients with suspected significant atherosclerosis and the improved accuracy of dual-source CT-derived calcium scores. ${ }^{2}$ As mentioned above, patients from our study having an Agatston score of 0 did not have significant stenoses at catheter coronary angiography. Theoretically, further CT coronary angiography (CTCA) investigation could have been omitted in almost one-fifth of patients. However (and as mentioned in the "Discussion" section of our paper ${ }^{1}$ ), up to $5 \%$ of patients having an Agatston score of 0 indeed have significant stenosis caused by non-calcified plaques. $^{3}$ Consequently, omitting coronary angiography when calcium scoring discloses no calcifications would result in up to $5 \%$ false-negative classifications. We therefore favour a calcium score not as the sole measurement but as an important supplement for CTCA in patients with non-evaluative coronary segments; patients with one or two nonevaluative segments at CTCA but having an Agatston score of 0 will have a high likelihood of having no significant coronary stenosis. We agree that the reported high negative predictive value of calcium scoring favours the test to be the initial imaging modality when coronary artery disease is suspected. However, we believe that it should be followed by CTCA in every patient.

\section{S Leschka, H Alkadhi}

Institute of Diagnostic Radiology, University Hospital Zurich, Zurich, Switzerland

Correspondence to: Dr S Leschka, Institute of Diagnostic Radiology, University Hospital Zurich, Raemistrasse 100, 8091 Zurich, Switzerland; sebastian.leschka@usz.ch

Competing interests: None declared.

\section{REFERENCES}

1. Leschka S, Scheffel H, Desbiolles L, et al. Combining dual-source computed tomography coronary angiography and calcium scoring: added value for the assessment of coronary artery disease. Heart 2008:94:1154-61.

2. Groen JM, Greuter MJ, Vliegenthart R, et al. Calcium scoring using 64-slice MDCT, dual source CT and EBT: a comparative phantom study. Int J Cardiovasc Imaging 2008;24:547-56

3. Haberl R, Tittus J, Bohme E, et al. Multislice spiral computed tomographic angiography of coronary arteries in patients with suspected coronary artery disease: an effective filter before catheter angiography? Am Heart J 2005;149:1112-9.

\section{CORRECTION}

doi:10.1136/hrt.2005.061150corr1

Partridge J. Radiation in the cardiac catheter laboratory. Heart 2005;91:1615-20. The link for the multiple choice questions was wrong. The correct link is http://heart.bmj. $\mathrm{com} / \mathrm{misc} /$ education. $\mathrm{dtl}$. 